\title{
Brasília: Superblocks in perspective
}

\author{
Frederico de Holanda*(1)
}

\begin{abstract}
The design for the Superquadra Norte 109 [North Superblock 109] of the Brasília Pilot Plan, Brazil's Federal Capital, has started from a critical appraisal of the existent superblocks and makes a proposal that intends to: 1 ) establish clear relations of the block with the surroundings, stressing the importance of elements as the entrance for vehicles, the bus stop and the connections with the local shopping and the club, through the dimension and form of places, the localization of facilities, public lighting and vegetation; 2) improve internal legibility of the block, by creating places clearly defined by the buildings, to which entrance doors open; 3 ) create a street system in rings, not in a tree-like one, which are common in the existing superblocks, to improve internal circulation; 4) locate facilities internal to the superblock accessible to its entrance, by recognising (against what was predicted) that non-locals use them; 5) establish a continuous system of sidewalks that privileges the pedestrian, not the vehicle, as is traditional; 6) use vegetation and illumination to reinforce the identities of places in the superblock; 7) implement a configuration that explores a clear variation in forms, dimensions and uses, which favour the identity and orientability of the block; 8 ) configure open spaces and localise facilities of the superblock to favour co-presence and co-awareness among the inhabitants and between the latter and those passing by.
\end{abstract}

Keywords: Brasília, modern urbanism, superblocks, urban configuration, morphological performance, Space Syntax Theory.

\section{Introduction}

Brasilia's "superblocks" are considered one of the main Lucio Costa's "inventions" in his "Pilot Plan" (henceforth "Plan") for the Brazilian Federal Capital (Costa, 1995). In four rows parallel to the Road Axis, the express road the cuts across the city form north to south, one of the two structural elements of the city (the other being the Monumental Axis, along which locate the main governmental buildings), they are the trademark of the residential fabric of his design for the city. Sixty odd years after the city's inauguration, what does the "superblock experience" tell us, by many considered as the dawn of a "new way of living in cities"? (Ferreira \& Gorovitz, 2009).

As of its foundation, the University of Brasília has received a valuable asset in plots distributed along the Plan, to be administered and explored according to the institution's needs. This was the case with the superblock 109 in the North Wing of the city (henceforth in its Portuguese denomination "SQN-109"), unbuilt until 1985. In that year the University has asked some of the staff of the Faculty of Architecture to design the urbanistic project for four superblocks and I have carried out the one concerning the SQN-109. 
There are strict norms concerning such designs: apartment building heights limited to six stories over pilotis; occupation ratio of the block space by the housing plots of circa $20 \%$ of the total block area; compulsory facilities, as the Kindergarten and the Primary School, the newsstand, the administration, the playground and the multi-sports court; a single entrance for vehicles.

Nonetheless, even obeying such rules there is a wide range of morphological possibilities. Today,

Page | 35 it is possible to assess the previous experience and hypothesise ways ahead to improve the blocks' configuration. The design that is presented in this paper illustrates one of such possibilities. However, before I embark on the discussion of the proposal itself, I discuss the theoretical framework considered.

\section{Design as a conjecture-test process}

Human practices - including the design and the production of places - constitute a virtuous circle, in Anthony Giddens' expression: we learn from our mistakes, from results which have been worse or better than those expected, we reconsider the precedents. Next time we will do different, in a continuous cultural evolution. Intervening in reality through design is like this: the virtuous circle in Figure 1 brings together Anthony Giddens and Bill Hillier, with reminiscences from Karl Popper, and represents design as a conjecture-test process (Giddens, 1984; Hillier, 1996; Popper, 2003 (1963)).

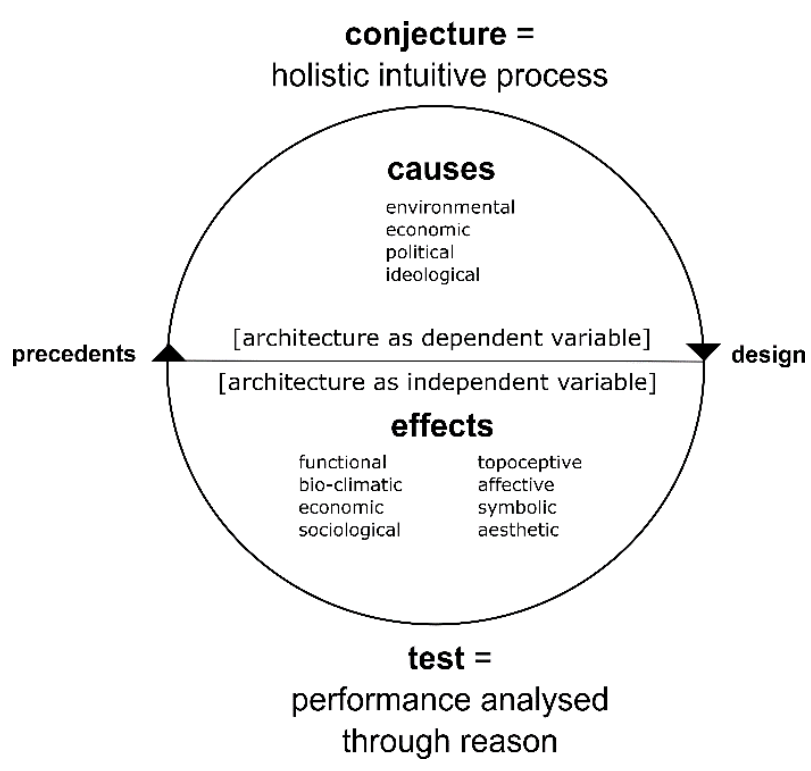

Figure 1 The virtuous circle of design as a conjecture-test process (inspired in Giddens, 1986, Hillier, 1996, and Popper, 1963). (Source: the Author)

The diagram re-takes the idea of causes and effects or architecture and inserts them in a continuous process. In other words, architecture, in the upper part of the circle, is considered a dependent variable, and, in its lower part, an independent variable. We design by considering precedents, even if they are constituted by unconscious, implicit, irreflexive knowledge. A task of scientific knowledge - systematic, conscious, reflexive - is to raise to the level of critical consciousness such savoir-faire, or, in Hillier's elegant formulation, switch from ideas we think with to ideas we think of (Hillier, 1996). When Lucio Costa designs his superblocks he submits in discursive knowledge the ideas he works with to formulate his proposal, i.e., ideology sensu lato (ideas in the broadest sense) as a determination of his design.

Here are the design principles of the superblocks he synthetically refers to: 1) a green belt; 2) cars in the centre, pedestrians in the periphery; 3 ) a single entrance for vehicles, avoiding through traffic; 4) "standard maximum height of, maybe, six stories over pilotis"; 5) "deep" schools, i.e., far from the vehicular entrance, presupposing they would be used only by locals; 6) "without 
pavements of any sort, nor curbs" (Costa, 1995). How do such attributes satisfy or otherwise social expectations in relation to architecture, not any longer as ideas, but as the lived experience of the blocks along their six decades of existence?

Except for principle " 6 " all others have been implemented; they constitute the genotype essence, structure - which underline the variety of the empirical examples materialised phenotypes. (The concept of genotype is omnipresent in Space Syntax Theory - henceforth SST initially proposed by Bill Hillier, Julienne Hanson and other colleagues at the Bartlett School of Architecture, University College London, and spread throughout research institutions worldwide, including Brazil (Hillier \& Hanson, 1984) $)^{1}$. From the experience of the implemented superblocks I explore the lower half of Figure 1: how do they affect our expectations in relation to its architecture? How, considering the critical assessment of the existing ones, may we create new precedents to inform (determine - if you like) new designs?

In empirical reasonings as this one, in which real examples come to the fore, not pure concepts, the starting point - surely - are the actual realizations in time and space. The design of the SQN109 has started, therefore, from the previous experience, but there is not here a wide examination of the many examples we have in Brasilia; rather, I have chosen to focus on one of them (with little exceptions) - the South Superblock 308 (henceforth SQS-308) - which is acknowledged as the most well-succeeded one. In considering the best example, we can detect the genotypical problems, which, as such, are structural, and therefore happen even in less emblematic cases.

I critically comment on the SQS-308 attributes, and then move on to present the SQN-109 design and discuss how I have tried to avoid the identified problems. For the sake of conciseness, the attributes come to the fore, not the aspects of performance, as in the lower half of Figure 1, which I shall call the "eight-function model" (see below). The reason is simple: same attributes are related to different aspects of performance, and to focus primarily on the aspects would result in undesirable prolixity.

Finally, I present the SQN-109 project as a design conjecture (upper part of Figure 1) at which I arrive through a holistic and intuitive process, informed by precedents, which feed on the critical appraisal of existent reality (lower part of Figure 1), through an analytical decomposition of the eight aspects of performance. The analytical knowledge that has made this critique possible was cumulative, informed by research. The conjecture, no, as Hillier observes:

The object of the architect's thought is a configuration, and a configuration is a whole entity, not an accumulation of parts. This of course is what we mean by a design conjecture. It is a configurational guess. It cannot be otherwise, since a configuration cannot be arrived at by an additive process. (...) A process of configurational conjecture cannot proceed other than non-discursively. It cannot therefore either follow a reasoned procedure, nor can it proceed additively from the bottom up. Design is by nature a holistic, intuitive procedure, and this conclusion follows from a reasoned analysis of the process of design (Hillier, 1996).

If the holistic conception is informed by intuition, its evaluation is informed by reason; if the former refers to a structured whole, the latter decomposes it into parts (or aspects, for that matter); in the evaluation process, software, analytical variables, measurements are applied. The design does not result from a single turn of the virtuous circle, but from as many turns as it proves necessary (or as many turns as time - or the client - allows for...), informed by the findings, as to performance, that tools and knowledge have made possible. At each finding, if a problem is diagnosed, our previous knowledge is enriched as to what to avoid and what to aim at, a new design conjecture is (intuitively) made, a new test is (reflectively) carried out - recurrently until the moment we feel no longer be able to advance in the design conjecture (limitations imposed by time, client, circumstances etc.) and at the state-of-the-art knowledge. It is impossible to estimate

${ }^{1}$ The founding book of the theory is HILLIER, Bill; HANSON, Julienne. The social logic of space. Cambridge: Cambridge University Press, 1984. In it for the first time are expressed in book form the axioms, methods and techniques of the theory, also known as the Theory of the Social Logic of Space. 
a posteriori how many turns in the circle we have performed - even less so a priori how many we will perform next time...

\section{The eight-function model}

The idea of aspects or dimensions of performance in architecture can be traced to as back as Page | 37 Vitruvius and his trilogy, or "three-function model" (my terms): firmitas (solidity, i.e., the architecture will not fall apart), utilitas (the architecture will be convenient to use) and venustas (the architecture will please the eye). In the 1970's, through endeavours to strengthen architecture as a discipline (Hillier \& Leaman, 1976), the classic essays by Bill Hillier and Adrian Leaman reembark on the idea: in How is design possible?(Hillier \& Leaman, 1974) they suggest a "fourfunction model" by which architecture implies four "modifiers" of the natural and the social environments in which it is inserted, another denomination for the same idea: the behaviour modifier, the symbolic modifier, the climatic modifier and the resource modifier. But if the aspects or dimensions are three, four, eight (as in Figure 1), or less, or more, it does not matter, the reasoning is the same, and it is in this route that we embark on here: we try to answer the questions of how does architecture affect our lives? or what type of social expectation is it able to satisfy? In the version I adopt since 2007 (F. d. Holanda, 2007; Holanda, 2010b) I summarise the aspects by means of questions:

Functional aspects. Does the place satisfy the practical exigencies of daily life in terms of the type and the quantity of spaces required by the necessary activities, and their mutual relations?

Bio-climactic aspects. Does the place provide adequate conditions of lighting, acoustics, air temperature, humidity, speed and quality?

Economic aspects. Are maintenance costs compatible with the purchase power of the people concerned?

Sociological aspects. Does the configuration of form-space (solids, voids and their relations) imply desirable ways of individuals and groups (social classes, genders, generations) deploying themselves in places and moving through them, and accordingly desirable conditions for encounters and avoidances and for the visibility of the other? Do the type, quantity and relative location of activities imply desirable patterns of utilization of places, in space and time?

Topoceptive aspects. ${ }^{2}$ Is the place visually legible, i.e., does it have a clear identity? Does the place offer good conditions for orientability?

Affective aspects. Does the place have a clear, strong affective personality? How does it affect people's emotional state - e.g., vis-à-vis solemnity, grandeur, coldness, formality, intimacy, informality, simplicity etc.?

Symbolic aspects. Is the place rich in architectural elements that remind us of other elements, on a larger scale than that of the place in question (e.g., a building representing the whole city), or of elements of diverse nature - values, ideas, history?

Aesthetic aspects. Is the place beautiful, i.e., are there characteristics of a structured whole and qualities of simplicity/complexity, evenness/dominance, similarity/difference, that evoke qualities of clarity and originality, and in turn pregnancy, implying autonomous stimulation of the senses beyond practical matters? Is the place a work of art conveying a world view? Does its form-space express a philosophy?

\section{General aspects}

The SQS-308 was one of the first blocks implemented in Brasília (1959) (Figure 2). The superblocks are square in plan, measuring $250 \times 250 \mathrm{~m}$, a limit defined by the surrounding pedestrian walk, much used for jogging. Figure 3 shows the SQS-308, with its only entrance for vehicles, and its immediate surroundings, with the local shopping, the church, the Park School (which serve the neighbourhood of four superblocks and in which, in the educational system of

\footnotetext{
${ }^{2}$ Topoceptive is a neologism in KOHLSDORF, Maria E. A Apreensão da Forma da Cidade. Brasília: Editora Universidade de Brasília, 1996, later to appear in enlarged form in KOHLSDORF, Gunter; KOHLSDORF, Maria Elaine. Ensaio sobre o desempenho morfológico dos lugares. Brasília: FRBH, 2017. The neologism means place perception by the senses, mainly vision. Kohlsdorf is inspired by Kevin Lynch's work but goes much beyond it.
} 
Brasília, cultural and sports activities take place) and the supermarket. Two other facilities outside the image complement the "borough", as Lucio Costa has expressed it: a club and a cinema.

Besides the schools, there are mandatory facilities within the superblock: playground, multisports court, and a newsstand. More recently a small building for the block administration has been included, as well as a taxi stop. Considering the limits of the surroundings pedestrian walk ( $250 \mathrm{x}$ $250 \mathrm{~m}=6,25$ hectares), the occupation ratio by the residential buildings of circa $20 \%$ is responsible Page | 38 for the praised "bucolic" atmosphere of Brasília's superblocks.

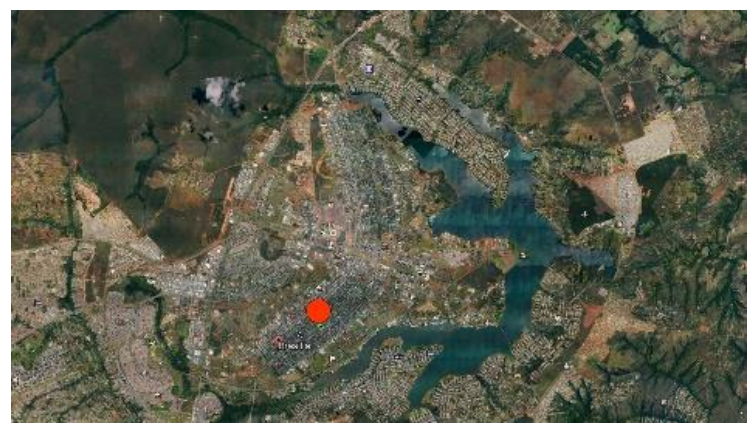

Figure 2 SQS-308. Localization at the South Wing of the Pilot Plan. (Source: elaboration by the Author, on the basis of Google Earth.)

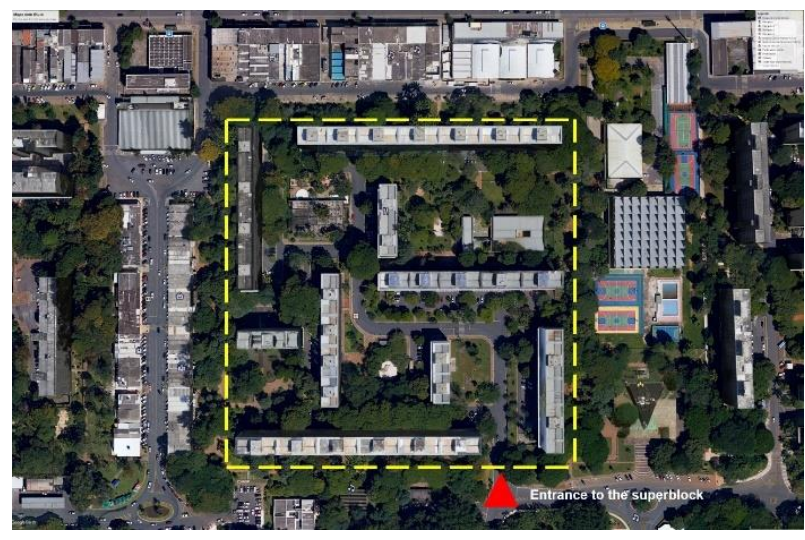

Figure 3 SQS-308. The superblock and its surroundings (local shopping, church, Park School, supermarket etc.). In yellow dashed lines, the location of the peripheral pathway, marking the $250 \mathrm{~m} \times 250 \mathrm{~m}$ limits of the superblock. (Source: elaboration by the Author, on the basis of Google Earth.)
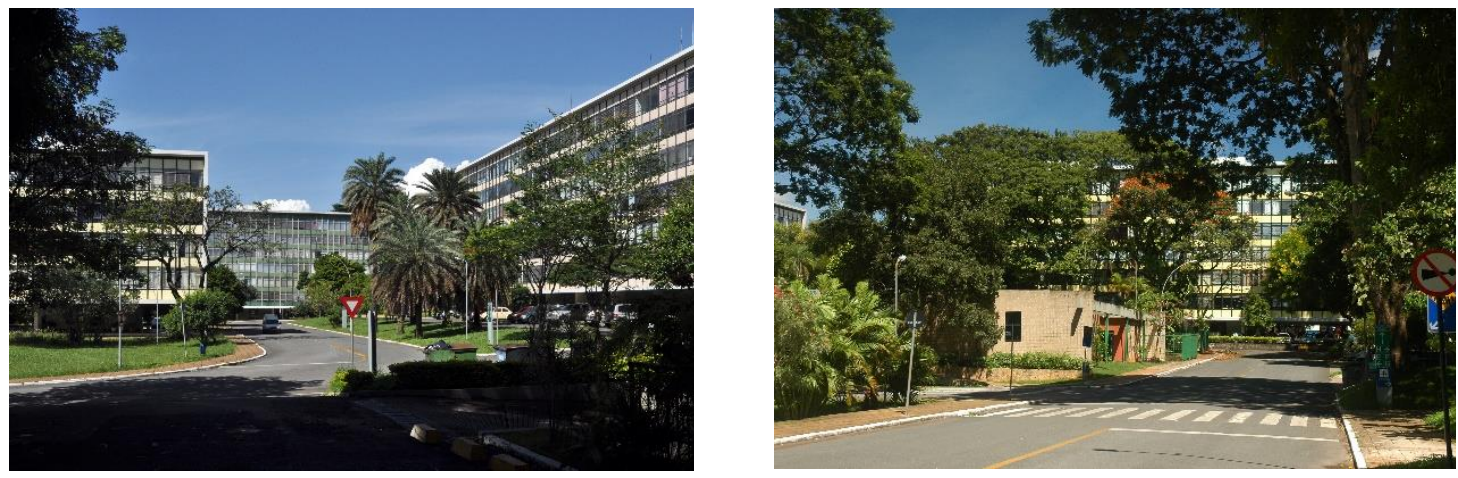

Figure 4 SQS-308. Two views of internal spaces of the block. (Source: the Author.)

Designed in 1985, the SQN-109 began its implementation in 1994. Figure 5 shows the location in the North Wing of the Pilot Plan, Figure 6 shows the design with the location of facilities, and Figure 7 the present stage of implementation, with its immediate surroundings. From the fifteen apartment buildings, ten are ready and inhabited. From the facilities, none has been built so far. 
Page | 39

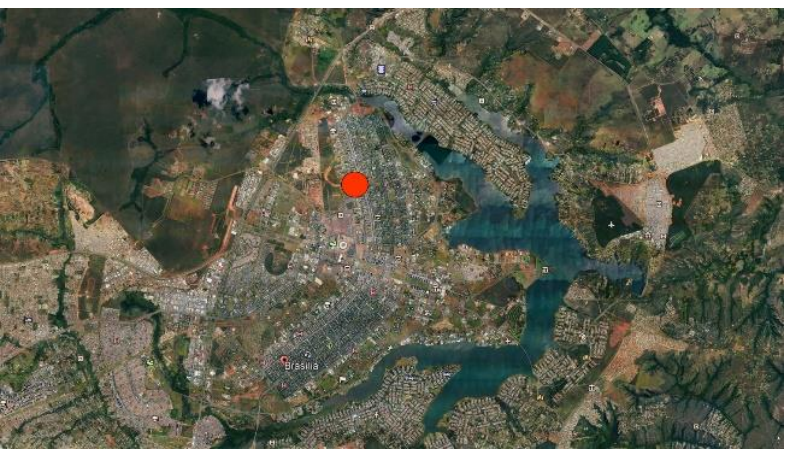

Figure 5 SQN-109. Localization at the North Wing of the Pilot Plan. (Source: elaboration by the Author, on the basis of Google Earth.)

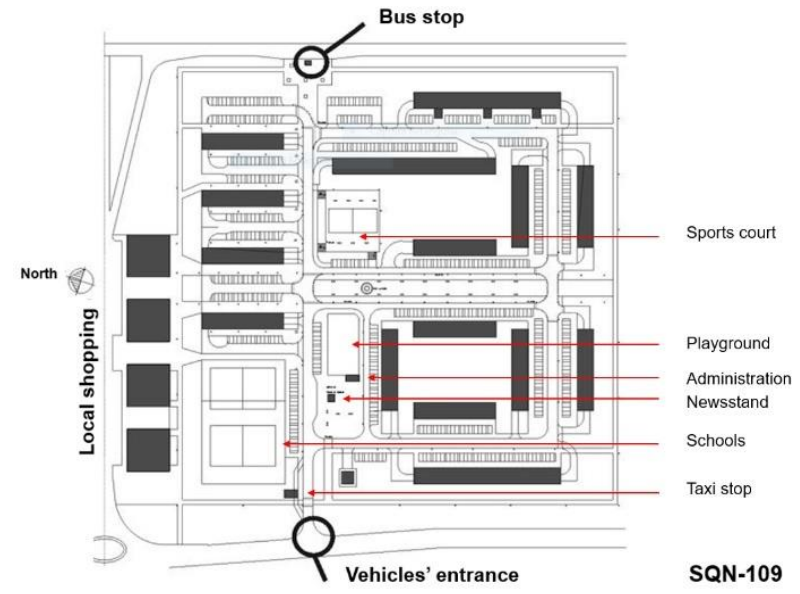

Figure 6. SQN-109. Overall design. (Source: the Author.)

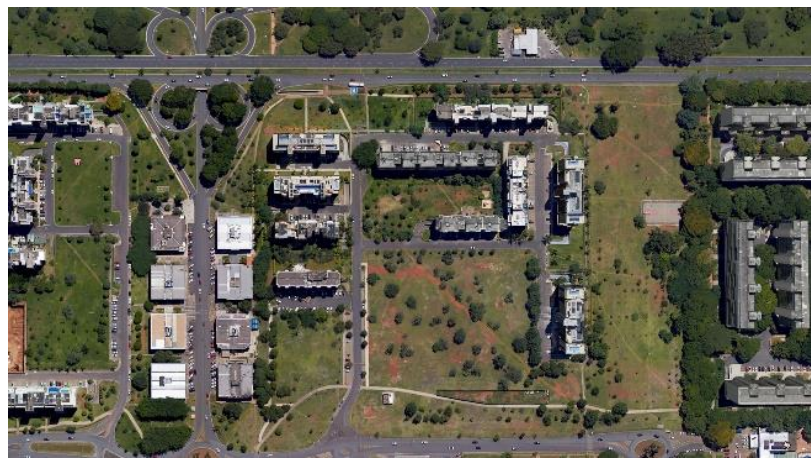

Figure 7 SQN-109. Current state of implementation (2021). (Source: elaboration by the Author, on the basis of Google Earth.)

\section{Entrance and street grid - vehicles and pedestrians}

In previous blocks together with the only entrance we have a tree-like street system, with various implications: 1) functionally, it demands longer routes to service vehicles as mail, delivering goods and trash-collecting vans, forces one to drive twice along the same street segments, which has also economic implications in the performing of these services; 2) topoceptively, the similar street segments' length and the zigzagging of the route cause disorientation (Figure 8). 


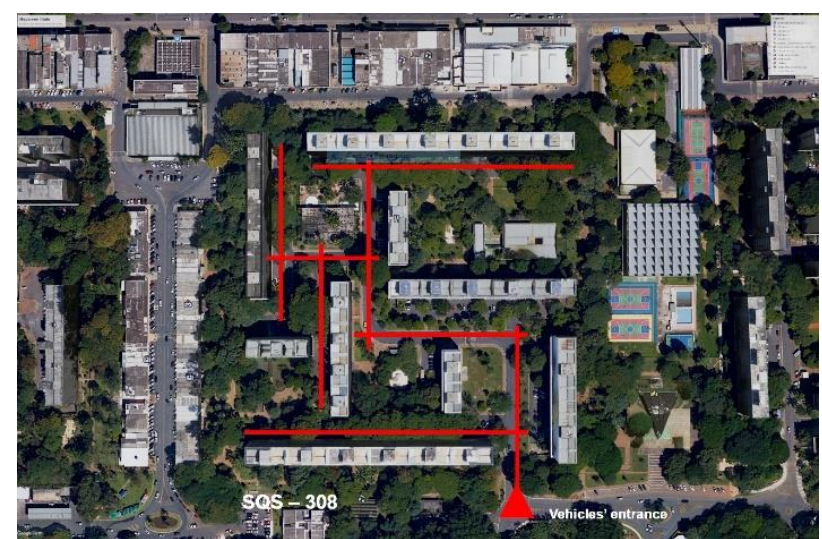

Page $\mid 40$

Figure 8 Labyrinthine and tree-like street system. (Source: elaboration by the Author, on the basis of Google Earth.)

In the SQN-109 I have kept the mandatory single entrance, but the street system is in rings, not tree-like (with few exceptions). There is a varied length of street segments, contributing to the topoceptive performance of the place concerning orientability (Figure 9): there is a reference to the classic Romans cardus maximus (north-south axis, which connects the interior of the block to the local shopping, to the north, and to the potential club, to the south) and the decumanus maximus (east-west, which leads to the bus stop, to the east, and to the entrance of the block, to the west); the two macro-elements, which do not exist in any previous superblocks, will confer a peculiar identity to the place, besides the legibility at the overall scale of the system.

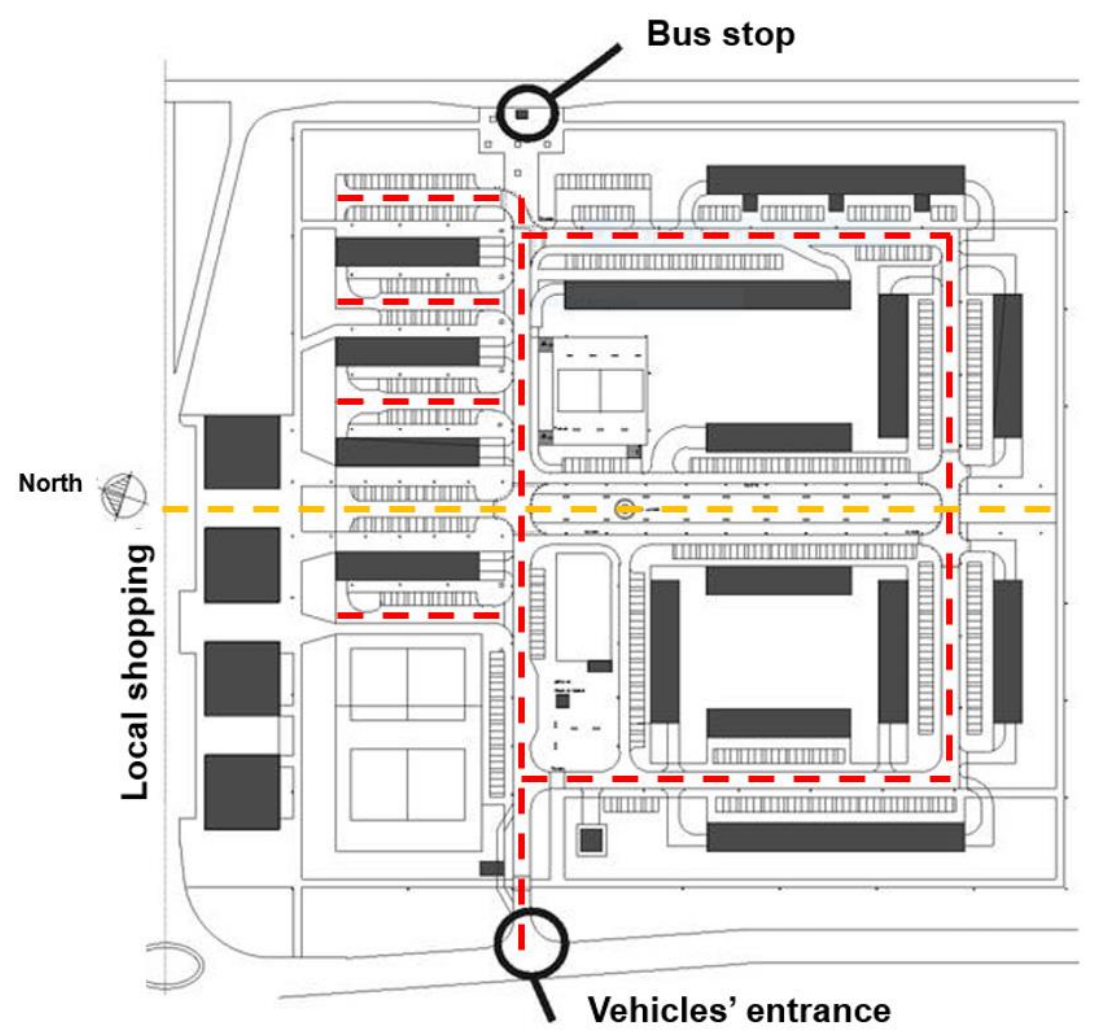

SQN-109

Figure 9 SQN-109. Circulation of vehicles and pedestrians. (Source: the Author.)

Topography has been ill-treated at the SQS-308, barriers have been created which perform badly visually and functionally (Figure 10). Path-walks are often blocked by walls and underground garage entrances. I tried also to avoid a frequent dichotomy found in other blocks (but not at the SQS-308), between arid spaces for circulation of vehicles and parking, and the beautifully gardened inner 
spaces of the place (Figure 11, Figure 12). Often enough, the former are $20 \mathrm{~m}$ wide, which makes it difficult for trees to be planted. At the SQN-109, these spaces are $50 \%$ wider $(30 \mathrm{~m})$, and this will result in environments as the one we have experimented at the Darcy Ribeiro Campus, University of Brasília (Figure 13; compare this to Figure 11). Bioclimatic performance is improved, by the shade, and the affective performance as well (i.e., from the emotional point of view), due to the strengthening of the so much appreciated "bucolic atmosphere". Thus, there is not a strong separation between spaces for pedestrians and spaces for vehicles - with the corresponding blurring of differences between mineral and vegetal.

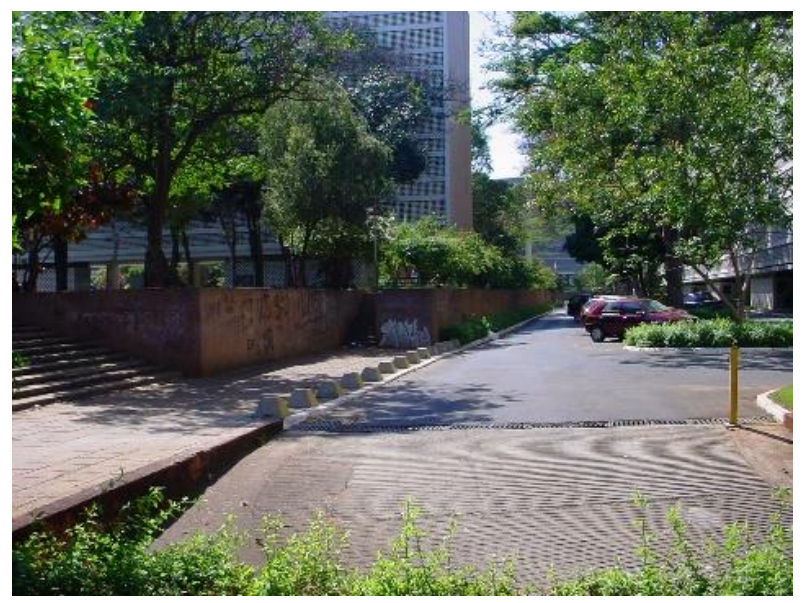

Figure 10 Ramparts and priority for vehicles in garage entrances. (Source: the Author.)

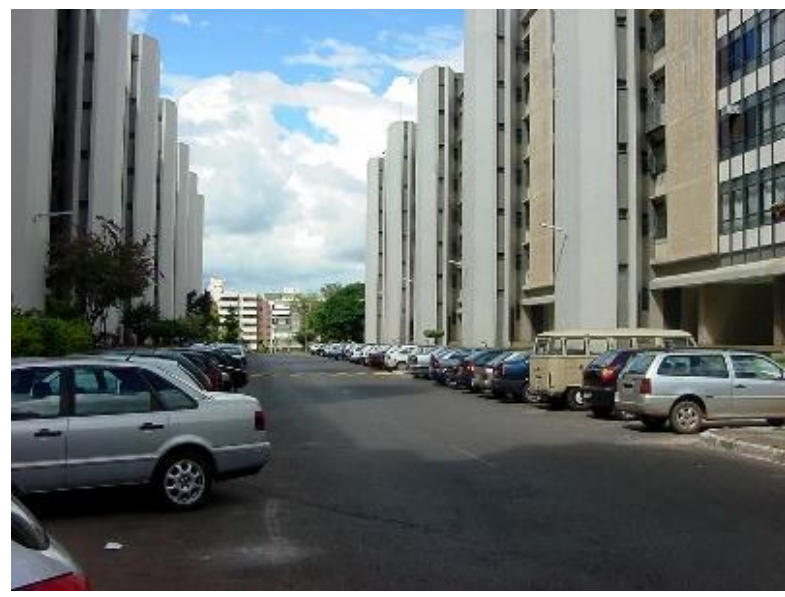

Figure 11 The arid space for vehicles circulation and parking. (Source: the Author.)

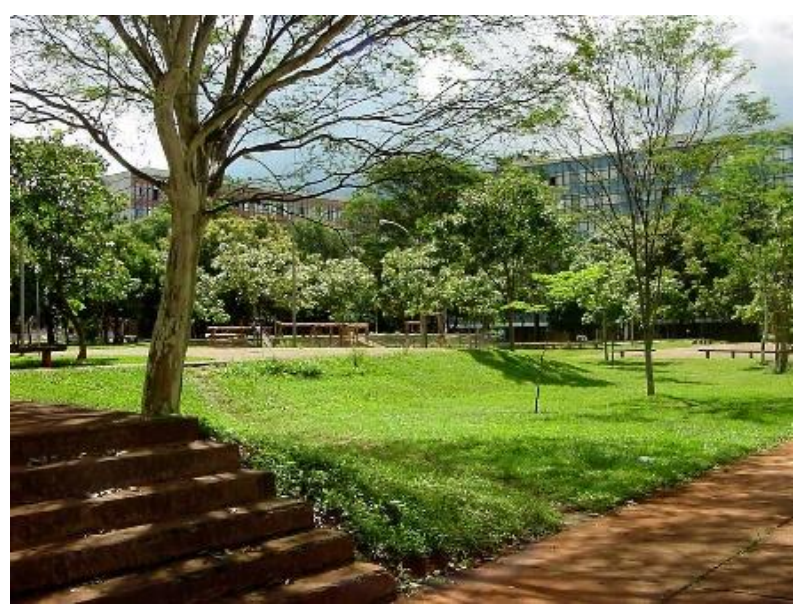

Figure 12 The bucolic space of the inner spaces. (Source: the Author.) 


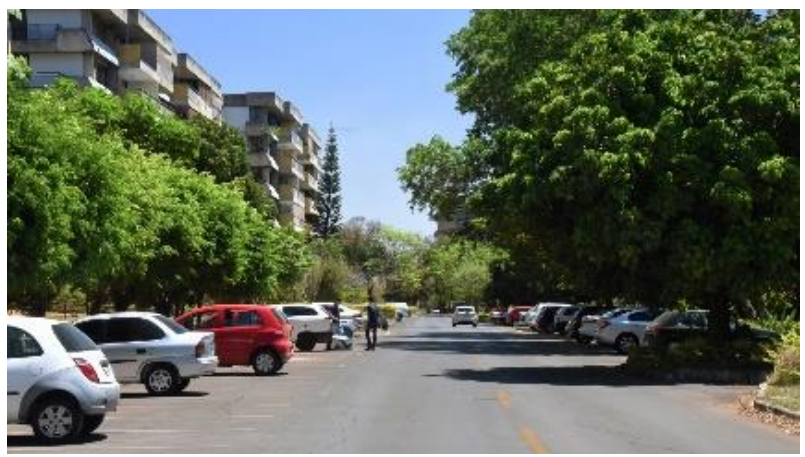

Page | 42

Figure 13 Street cross-section at the Darcy Ribeiro Campus, University of Brasília. (Source: the Author.)

On the other hand, at the SQS-308 vehicles zigzagging is mimicked in pedestrian routes, affecting functional and topoceptive performances. The celebrated permeability of the free continuous open space granted by the pilotis is more mythical than real: first, pilotis have progressively been occupied by the porter's apartment and by a room for collective parties of the inhabitants; second, the floor of the pilotis level often rises above surrounding ground level in order to let light in to the underground garages, and it is often accessed by stairs; third, routes are not spatially legible, i.e., they are not clearly sanctioned by a clear interplay of volumes and voids granted by the buildings. To go from the inner spaces of the block to the local shopping or to the bus stop navigating up and down stairs or going through a sequence of unimportant spaces is one thing; doing this along a spatial axis clearly defined by built volumes, as along our cardus maximus, is something else altogether (Figure 14).

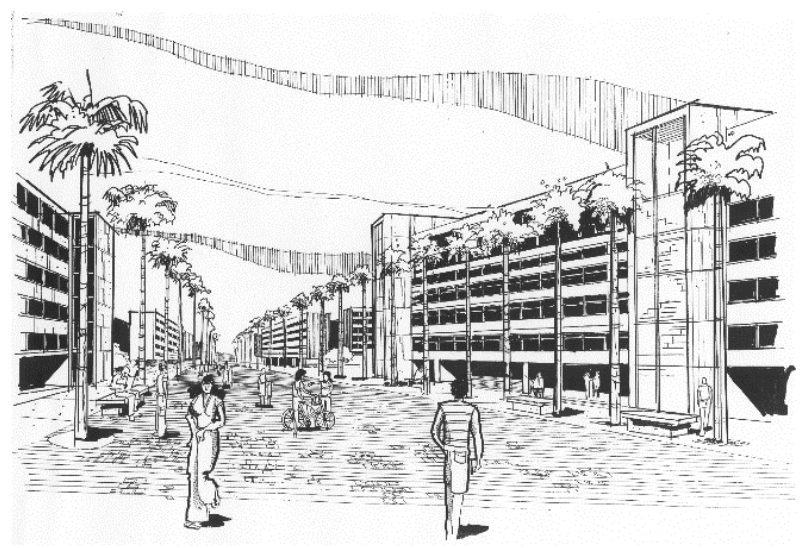

Figure 14 Sketch of the proposed cardus maximus, cutting across the superblock from north to south, leading to the local shopping. (Source: drawing kindly prepared by Eliel Américo da Silva for the Author.)

The two large axes signal the important relation with two magnets of the surroundings: the bus stop and the local shopping. Such a generous connection is denied in previous superblocks, volumes and spaces are thought in themselves, not in relation to the context, as at, for example, the SQS109 (Figure 15, symmetrical to our project, but now in the South Wing of the Plan): two large buildings block the perception of the magnets from the inner spaces of the block. 
Page | 43

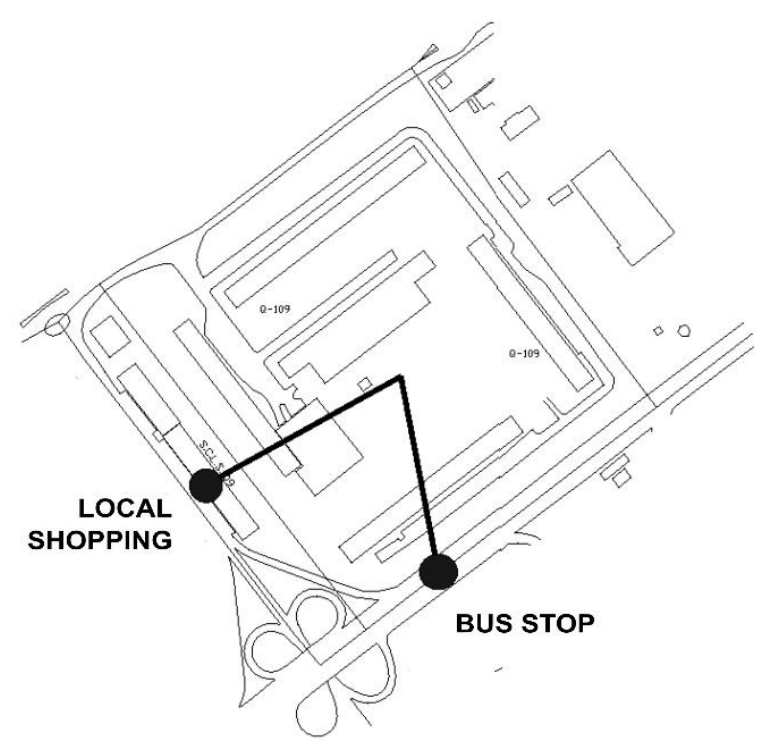

Figure 15 SQS-109. Denial of the clear relation with important magnets of the surroundings. (Source: the Author.)

Formalizations allowed by SST contribute to further characterise the introspective and labyrinthine configuration of the SQS-308, as compared to the SQN-109; this is done through the axial map (Figure 16) and its corresponding measures. The axiality is a technique from SST by which we capture the possibilities of movement, now concerning pedestrians, from all points to all others in the case under study; the result is systemic, the processing reveals the field of possibilities of movement by coloured lines, from the hottest (in red) to the coldest (in deep blue): the hotter the colour, the more accessible the line is to the system (it is easily reachable, in terms of less turns, from any other line in the system), and vice-versa, the colder the colour, more route inflexions we have to perform. In the abstraction performed here, I have considered only the built volumes as barriers, thus simplifying the phenomenon by ignoring 1 ) the permeabilities granted by the pilotis for the reasons above, and 2) the barriers formed by walls and ramparts, as of those of the SQS308, Figure 10: I was interested in contrasting the possibilities of movement only through the macro-structure constituted by the buildings.

The result speaks loudly (Figure 16). First, at the SQS-308 there is no single example of a route (an axial line) that cuts across the whole block: one or both endpoints always end at a façade of a building inside the block; at the SQN-109, there are two bunches of lines which cut across the block along the cardus' and the decumanus' spaces, and there are other lines that do this in other positions. Second, the frequent blockages commented concerning vehicles repeat themselves as far as pedestrians are concerned in previous blocks, thus making the axial system of our SQN-109 much more integrated than the one of the SQS-308: this is revealed by the measure of integration from SST, of 8.03 in average for the SQN-109 and 3.77 for the SQS-308. In other words, besides being difficult to reach the surroundings, thus signalling the introspective character of the SQS-308, the internal spaces of the block are also separated among themselves by a much greater number of route inflections. 

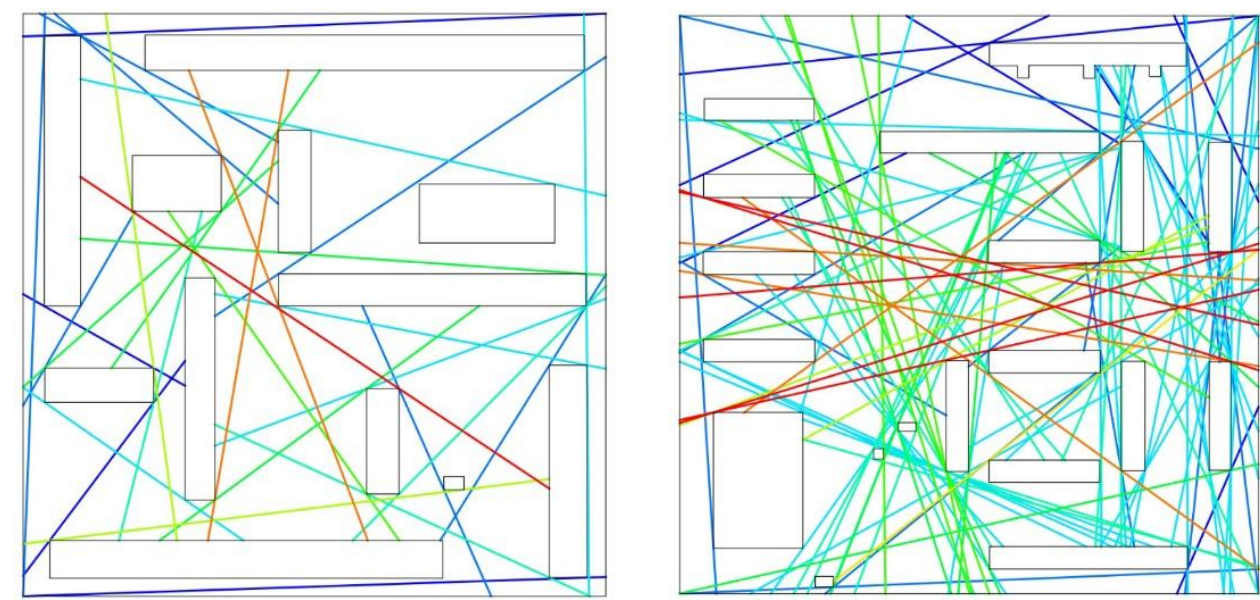

Figure 16 Axial maps of the SQS-308 (left) and of the SQN-109 (right). (Source: the Author.)

Finally, the north-south axial space, with very narrow traffic lanes $(2,5 \mathrm{~m}$ wide) for the exclusive access to parking spaces, in both sides of a wide pedestrian lane $20 \mathrm{~m}$ wide, an axis that is furthermore decorated with palm trees and sculptural elements as a fountain, would be an unprecedented element in Brasília's superblocks. If the symbolic performance of a place depends on elements strong enough to represent the whole through the part - the definition proper of symbolism - the cardus maximus of the SQN-109 is our favourite candidate.

\section{Localization of schools}

The localization of schools deep at the block, presupposing that only children who live in the surroundings would use them proved wrong. This was a functional mistake resulting in a strong movement of cars through the block and a nuisance to the inhabitants. The mistake happens in all previous superblocks (Figure 17). In no city, this one included, the orthodox logic of the neighbourhood unit, by which the local facilities are used by... the locals, works. Choosing to which school parents take a kid results from a series of factors, not from the distance to the facility (this has also happened to our kids, while we were living at the North Wing, at another superblock): the quality of the school, the convenience of the location along the route to work of the parents, the fact that the school receives students who live in the satellite nuclei but who work in the Plan but not within the superblock etc. At the SQN-109 the schools locate close to the entrance (Figure 18). There is a topoceptive plus: as special buildings, they will contribute to strongly signal the access to the block for those passing by.

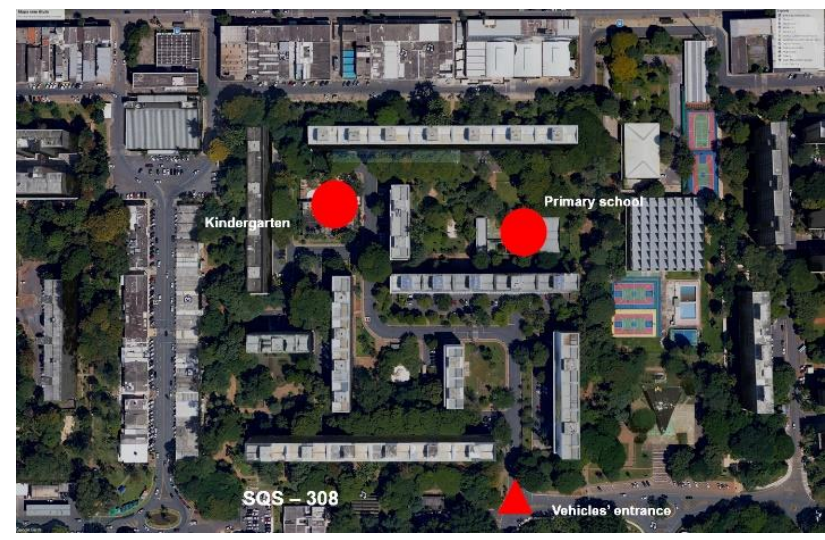

Figure 17 SQS-308. Localization of schools. (Source: elaboration by the Author, on the basis of Google Earth.) 
Page | 45

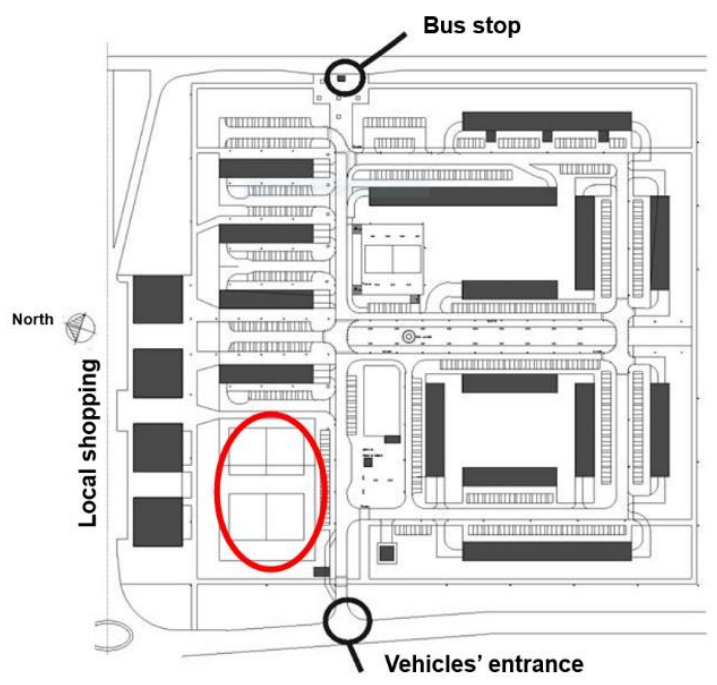

SQN-109

Figure 18 SQN-109. Localization of schools. (Source: the Author.)

\section{The order of the open spaces}

The order of the superblock open spaces can be examined in "gross-tunning" and in "finetunning" (note that the two superblocks have almost exactly the same occupation ratio of residential plots concerning the total superblock area: $21,5 \%$ for the SQS-308, 20,4\% for the SQN109). ${ }^{3}$ In the case of "gross-tunning" analysis I consider only the spaces defined by the volumes of the apartment buildings, units which are represented synthetically by ellipsoids (Figure 19, Figure 20); they are macro-morphological units, perceived as if our stance would locate at a height immediately above the roof of the schools, which are single-storied (the strength of the spatial definition of the six-story buildings above the height of the schools justifies this unorthodoxy). At the SQS-308 and in other blocks in general, in this tunning, there is no clear differentiation among open space units - they have similar size and form (Figure 19). At the SQN-109 (Figure 20), on the contrary, there are four main types of spaces, of different sizes and forms, thus favouring topoception: 1) two large axial spaces - the cardus and the decumanus - which cut across the block (in red); 2) the axes of vehicles' access to the residential parking spaces (with variation in size, in yellow); 3) a somehow interior space of a secondary block inside the superblock, without vehicular access, thought for orchards and gardens implemented by the inhabitants, something which is actually already being done by the locals (in green).

\footnotetext{
${ }^{3}$ The reasoning is close to the one concerning the convex analysis from SST. But in the theory, space can be decomposed in onedimensional units (the axial lines, as seen above), but also in two-dimensional units, and this in two ways. Convex spaces correspond intuitively to the notion of "place" at a small urban scale: there must be conditions of co-presence among the subjects who are inside them, and who may walk in straight lines among themselves (formally, in a convex space we can insert a convex polygon - i.e., one without concavities, the perimeter of which, therefore, cannot be crossed by a line in more than two points). However, here, the "grosstunning" analysis disconsiders even low height buildings because, at a larger scale, it is useful to take into account spaces which are defined only by the six-stories apartment edifices. The "fine-tunning" analysis (see below) is closer to the convex analysis of SST, but again, there is an intuitive approximation aiming at the understanding of the non-specialist reader: the figures illustrate the argument, ellipsoids, not polygons, are enough to suggest these micro-morphological units.
} 


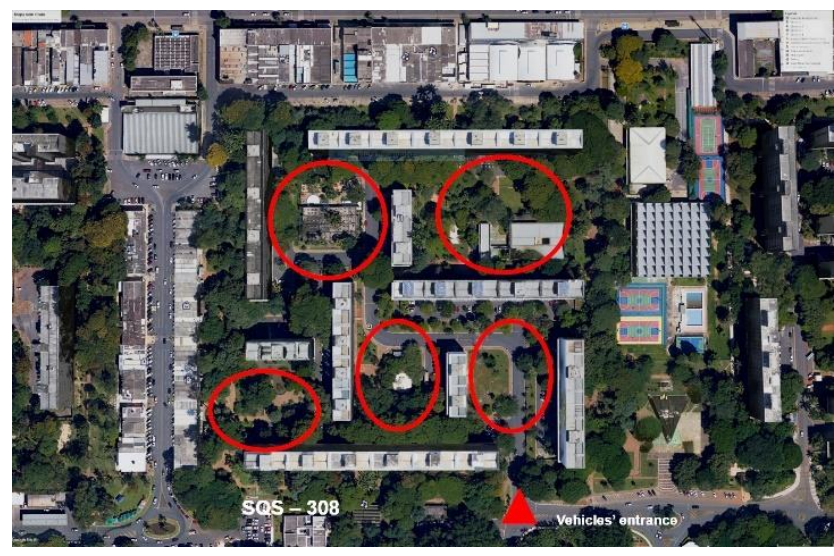

Page | 46

Figure 19 SQS-308. Macro-morphological units of open spaces. (Source: elaboration by the Author, on the basis of Google Earth.)

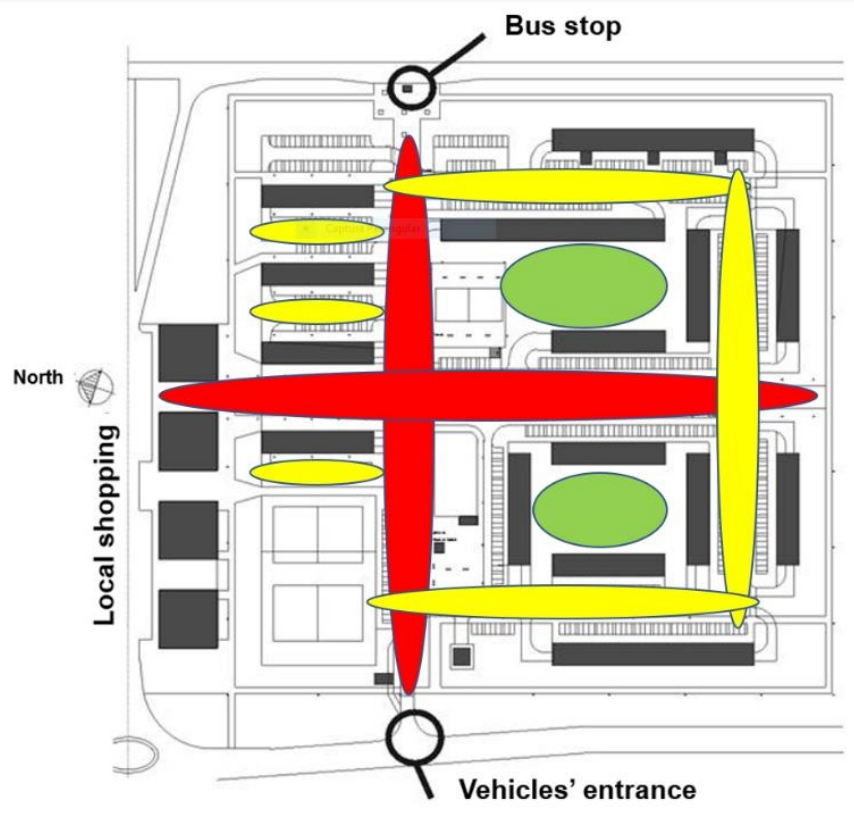

SQN-109

Figure 20 SQN-109. Macro-morphological units of open spaces. (Source: the Author.)

In "fine-tunning", now including the school buildings, the SQS-308 is, again, very fragmented, comparatively to the SQN-109. In the former (Figure 21), there is a proliferation of small spaces (12) defined always on one side by the lateral blind façades of buildings, as it was fashionable in classic modern edifices; in the latter (Figure 22), this type of spaces are half of those in number (6), and, more important, they are so small as to go practically unperceived. (If blind façades are common in the older buildings of the Pilot Plan (Figure 23, left), this fortunately does not happen so often anymore, as windows and verandas also open to these lateral façades, defining a more gentle open space configuration - the famous "eyes to the street" of Jane Jacobs' (Figure 23, right), (Jacobs, 1961)). 
Page | 47

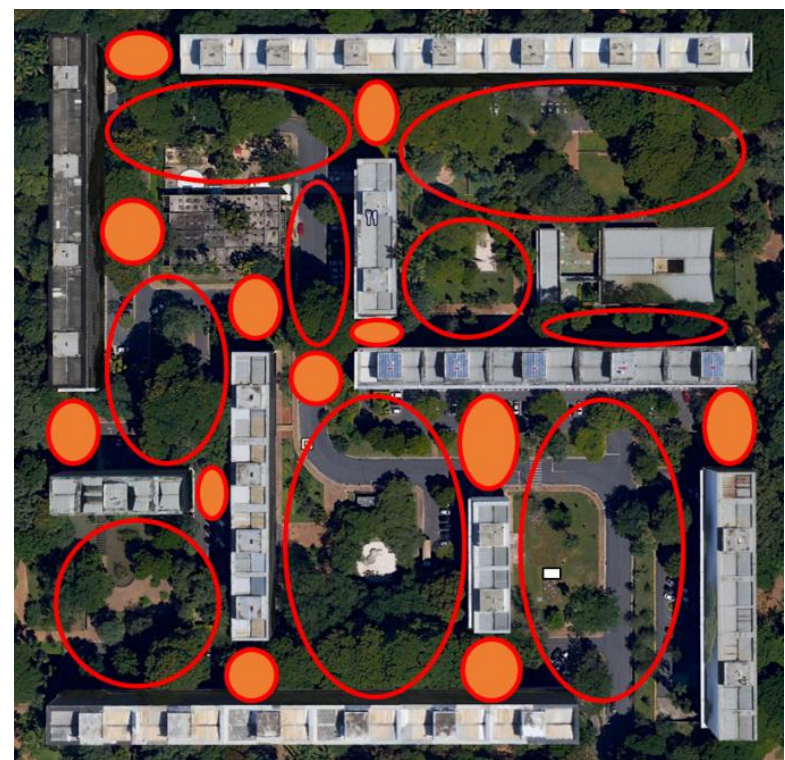

Figure 21 SQS-308. Spatial decomposition in "fine-tunning". Spaces defined by at least one blind façade (sometimes two) are marked in orange. (Source: elaboration by the Author, on the basis of Google Earth.)

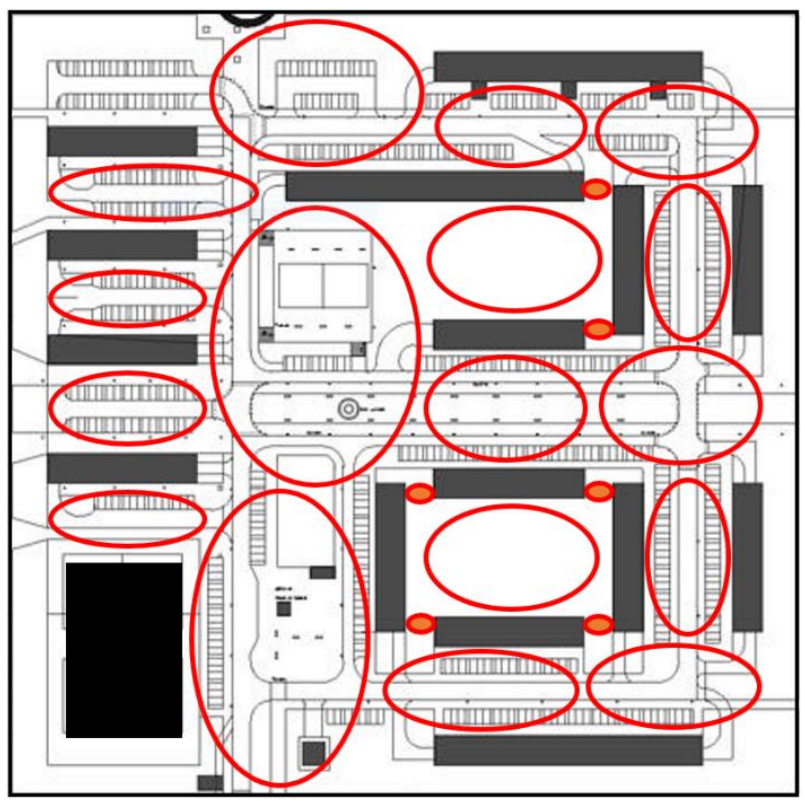

Figure 22 SQN-109. Spatial decomposition in "fine-tunning". Lateral façades, as in almost all recent buildings, are not blind. (Source: the Author.)
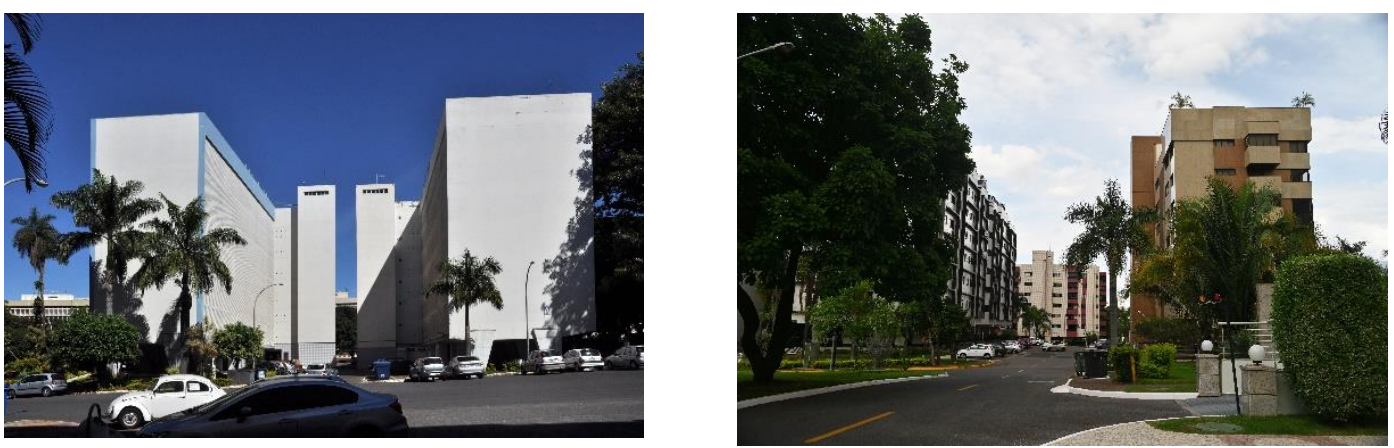

Figure 23 Blind façades of classic modern buildings from the 1960's (left, SQS-108) and more recent buildings without them, from the early 2000's (right, SQN-109). (Source: the Author.) 
Finally, there is one more analytical category that adds information to this comparison: the isovists. The concept comes from Michael Benedikt, but has been incorporated within the procedures of SST:

... I cannot see everything from where I am. Once you become aware of the limited amount of space you can actually see, and then think of it from the outside as it were, as a volume or body of space with you embedded in it, then you can take the next step and determine its objective size and shape. More formally: the body of space visible to and from a point $\mathrm{x}$ is called the isovist at $\mathrm{x}$. (...) Isovists belong to the world, "waiting" for eyes [original italics](Benedikt, 2020).

The software Depthmap(Turner, 2004), constitutive of techniques from SST (Hillier, 1996), allows for the comparison of isovists from all points to all other points of a certain place: "points" here are the cells of a grid that is defined according to the size of the place under analysis and the processing capacity of the computer available - in the present case, I have defined a $2 \times 2 \mathrm{~m}$ grid. Figure 24 compares the isovists of the two superblocks, now in "fine-tunning", in which all buildings, including the small newsstand are considered. Warmer colours represent cells which are mostly visible from all points of the place (this is called visual integration Rn); colder ones, the opposite. Note: 1 ) there are four areas in red of similar importance at SQS-308 (Figure 24, left); this repeats, at this level of fine-tunning, the idea of redundancy of information commented on above; 2) the points of view from the "hotspots" at SQS-308 do not connect important elements of the configuration: they are blocked by buildings or reach head on the fence of the school, to the right of the image. At the SQN109 (Figure 24, right) the central space is clearly outstanding, revealing the importance of the two perpendicular axes and, more so, the point where they cross. Also, from this spot we see the most important magnets of the surroundings: the bus stop, the entrance to the block, the local shopping - there is a clear definition of a strong focal point, if Kevin Lynch's jargon is to be used, whereas at the SQS-308 we have somehow four weak ones (Lynch, 1960).
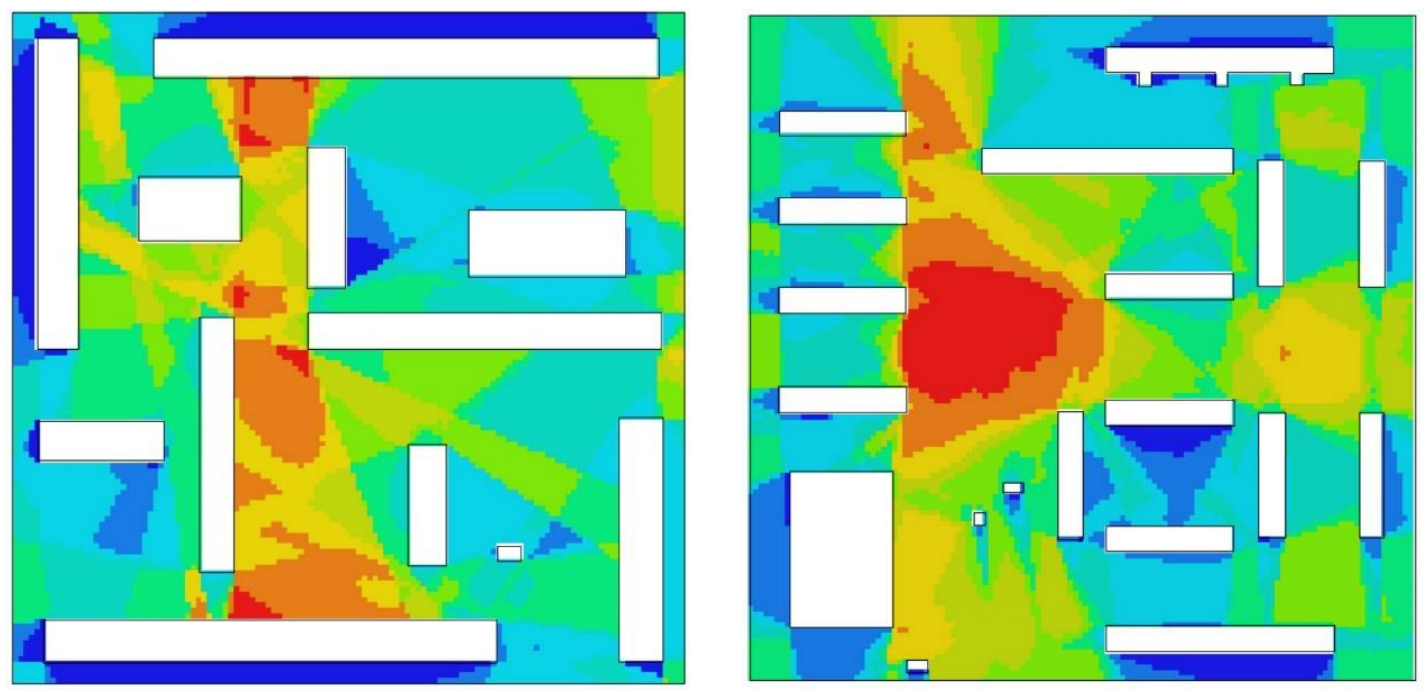

Figure 24 Isovists from all points to all others (visual integration Rn), from the SQS-308 (left) and from the SQN-109 (right). (Source: images kindly prepared by Valério de Medeiros for the Author.)

Furthermore, the two major elements differ. The cardus maximus (north-south), besides performing the functional role of connecting the block to the local shopping, is more bucolic, aiming at passive leisure, rest, sitting down in benches under the morning and the afternoon soft light, when the place is in shade. In the south-north direction (Figure 25, right), the distance in between volumes shrinks progressively, and, in the contrary, in the north-south direction (Figure 25, left), it broadens progressively, favouring different isovists' forms, depending on the direction of the regard, thus contributing to orientability (topoception). A comparison of the isovists taken from the peripheral pathway, in both directions - north-south and south-north - shows the difference in form of the perceived space. The decumanus maximus has a distinct character (see below). 
Page | 49
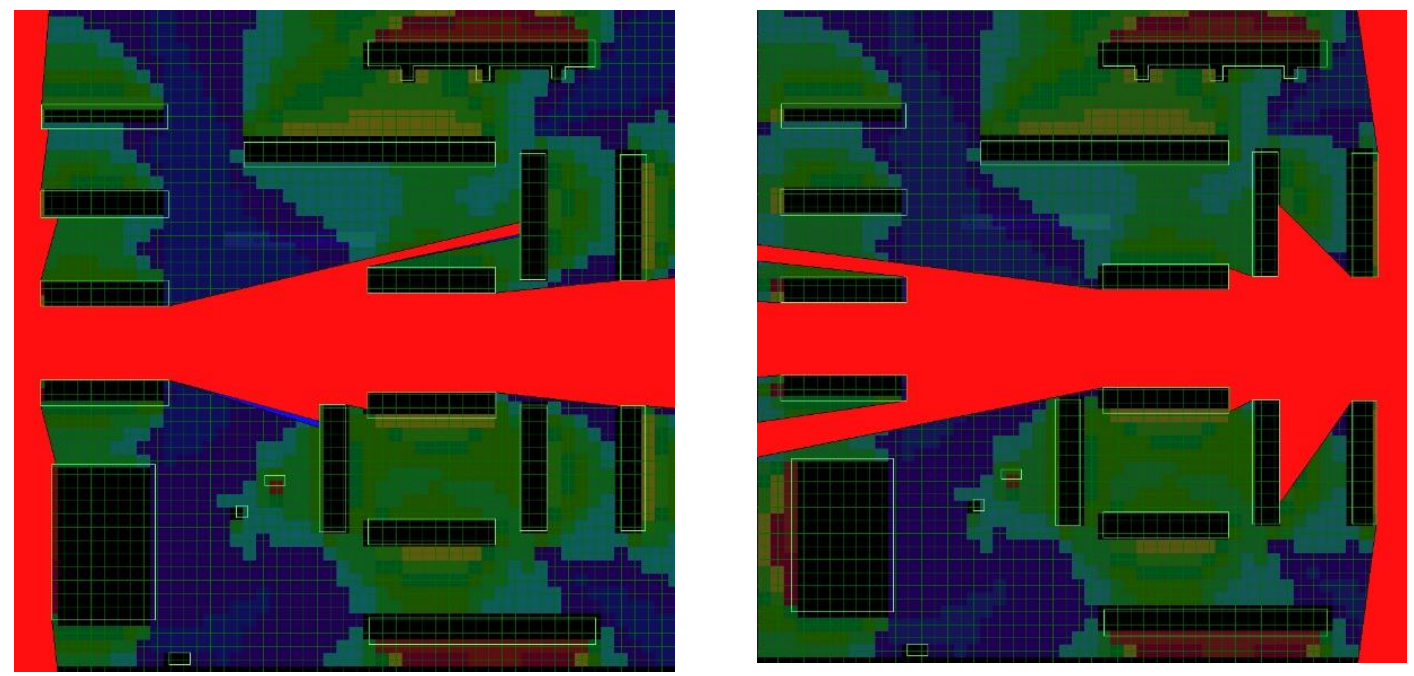

Figure 25 Isovists taken from the endpoints of the cardus maximus: north-south (left) and south-north (right). (Source: the Author.)

The exploration of laws of plastic composition, e.g., similarity $x$ difference, and common $\mathrm{x}$ special (Kohlsdorf \& Kohlsdorf, 2017), has been explored, more concerning the open space units than concerning the volumes (the latter are pre-determined). The two distinctive axial spaces, inspired by the classic Roman tradition, convey a good aesthetic performance, which, naturally enough, will depend on other aspects - e.g., if the precious landscape design by my colleague Vicente de Paulo Quintella Barcellos be implemented. Also in the aesthetic field, the philosophical worldview is rather Apollonian than Dionysian - e.g., the economy of means, the orthogonal fabric, the formation of a small number of orthogonal spatial units etc. Except orthogonality, all this contrasts with the SQS-308 configuration.

\section{The distribution of facilities}

At the SQS-308, facilities spread throughout the block, are invisible among themselves (Figure 26), and this results in the reciprocal invisibility of the varied subjects who use the place (or use the immediate surroundings): babies with nannies or parents, children, in the playground, adolescents and adults, at the sports court or at the pond or at the newsstand etc.

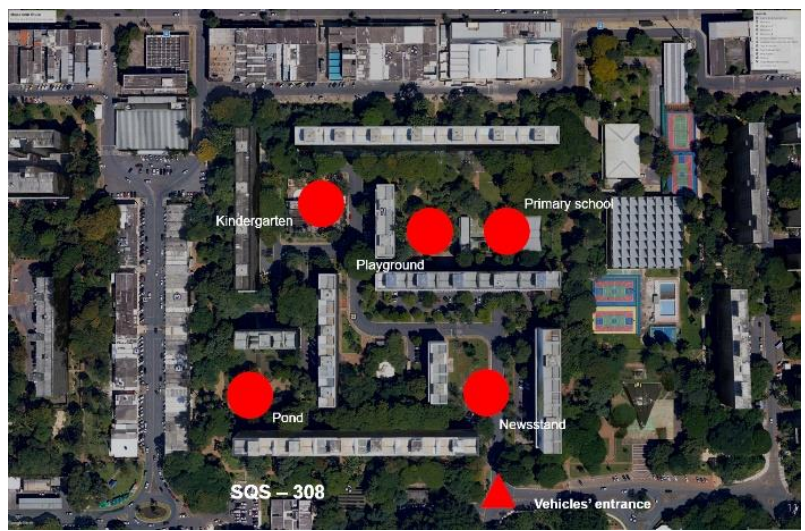

Figure 26 SQS-308. Localization of facilities. (Source: elaboration by the Author, on the basis of Google Earth.)

At the SQN-109 the decumanus maximus has an important sociological role - it is the space of greatest urbanity in the block (Figure 27). First, it allows co-presence and co-awareness - i.e., conditions of mutual accessibility and visibility - among different subjects who become mutually invisible, by spatial configuration, at the SQS-308; along the decumanus locate the main nonresidential facilities that generate presence in public open spaces: the sports court, the playground, 
the administration, the newsstand, the schools and the taxi stop. The plots for the two mandatory school units are contiguous (which never happens in other blocks) so that we can minimize the long blind walls of the isolated plots - fashionable in modern urbanism.

Moreover, the large axial space favours the interface between inhabitants and strangers, for it will be used by those who take buses, who step down from them at its eastern endpoint, and walk, through the block, along its internal pathways, to jobs located to the west of the place. This, again, Page | 50 is unprecedented: because of aspects already commented, major pedestrian flows happen along the peripheral pedestrian walks. The mutual accessibility and visibility among diverse social subjects enrich sociability by bringing together is same spaces inhabitants and people just passing through.

Topoceptive performance is added to the sociological one: the decumanus is the widest and longest space of the block, its configuration defined mostly by façades of the six-stories apartment buildings, but also by the single-storied schools, administration, newsstand, the bus stop and the taxi stop. The $360^{\circ}$ degrees isovist from the point where the cardus and the decumanus cross - truly a "spatial explosion" - illustrates the importance of the two macro-elements of the superblock (Figure 28). Nothing similar occurs at the SQS-308. Figure 29 illustrates the whole superblock through a bird's-eye view perspective.

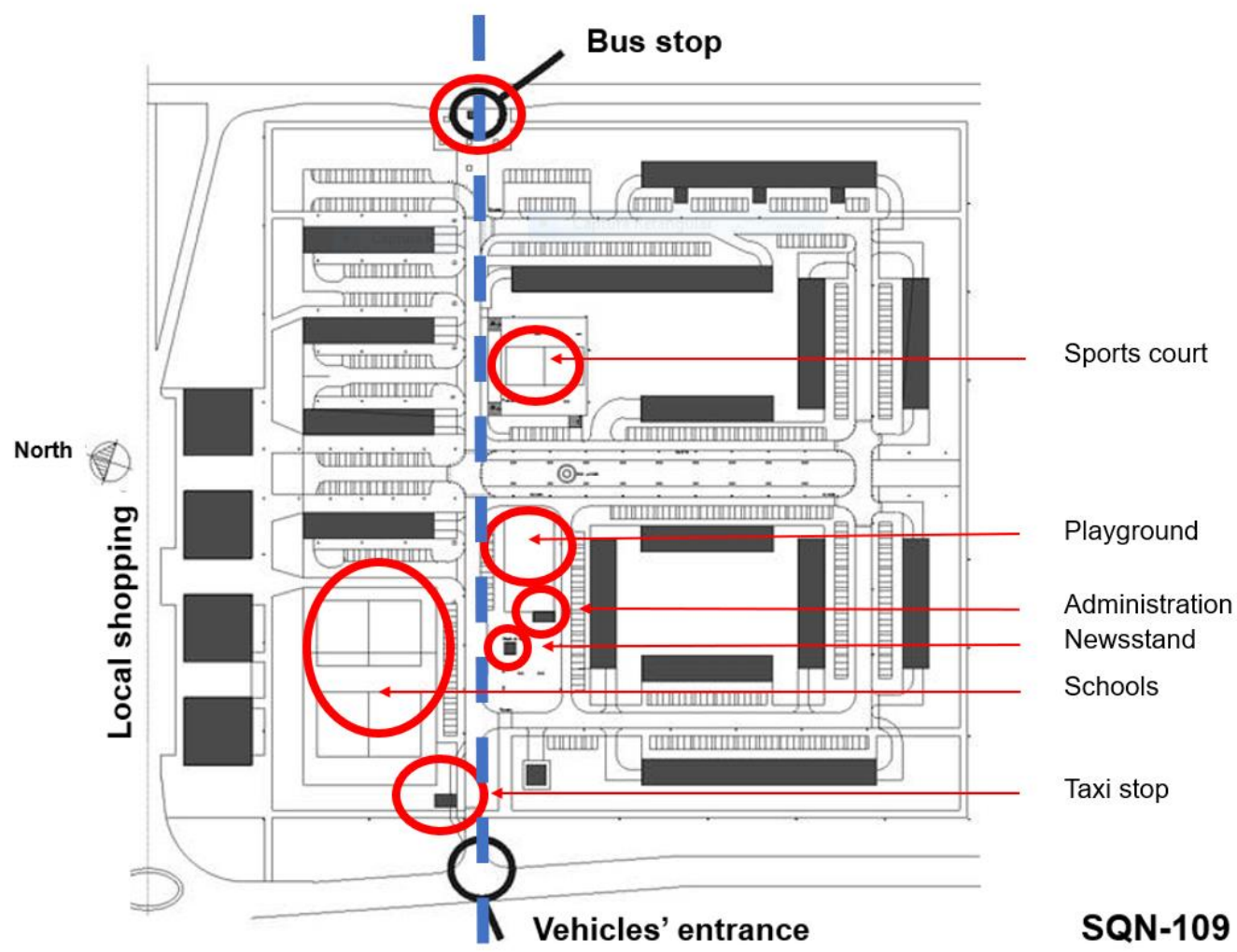

Figure 27 SQN-109. Facilities along the decumanus maximus. (Source: the Author.) 
Page | 51

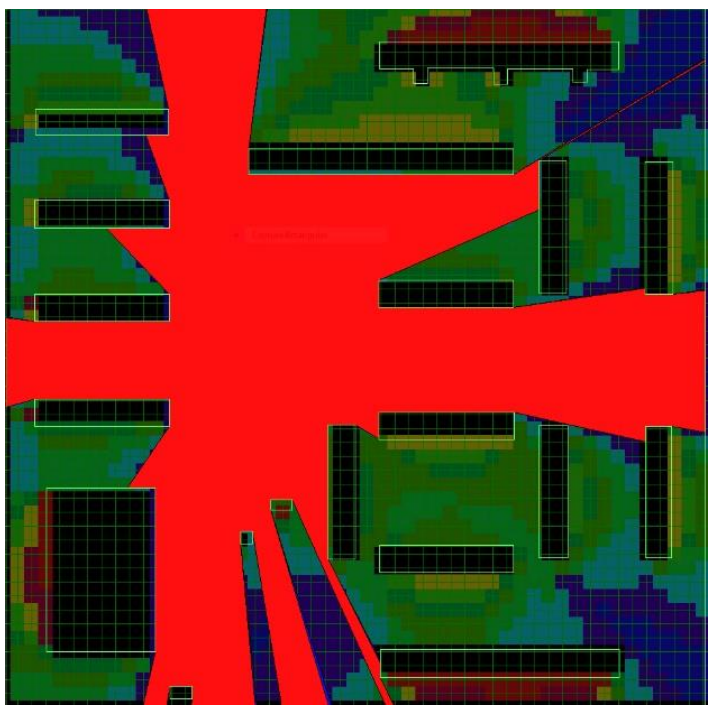

Figure 28 Isovist taken from the crossing of the cardus maximus with the decumanus maximus - "spatial explosion". (Source: the Author.)

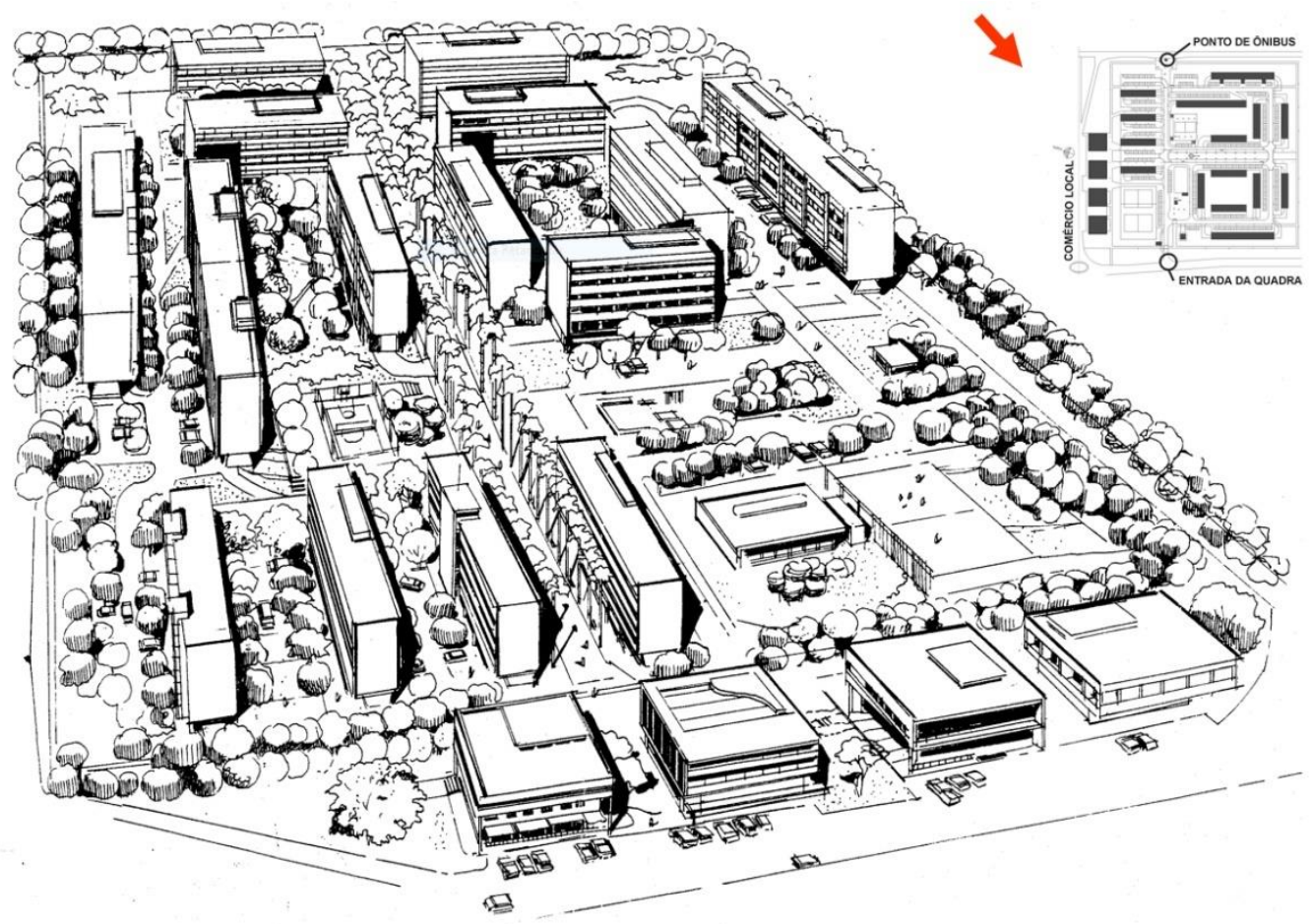

Figure 29. SQN-109. Bird's-eye view of the superblock. (Source: drawing kindly prepared by Eliel Américo da Silva for the Author.)

\section{Use of public space}

It is soon to evaluate how the design proposal for the SQN-109 will favour (or otherwise) the use of public space by inhabitants and strangers, due to the incompleteness of the block. However, despite being inhabited by high-middle classes (Figure 31), who would rather frequent closed, private spaces (Holanda, 2002), the use of public spaces in Brasilia's superblocks dismantles the myth of "desertification", "Ioneliness", "sadness" of those who inhabit them, in this city so rich in myths - of demonization or sanctification, depending on the prejudices of their spokespersons: 
In Brasília, the outdoor city public of other Brazilian cities has all but disappeared. ... Social life oscillates unremittingly between work and residence. ... Hence, the overwhelming sense of monotony and sameness that Brasilienses experience in the city. (Holston, 1989, p. 153, 163, 312) (Holston, 1989).

Quite the contrary, such bombastic statements do not match empirical evidence: open spaces of the superblocks are used by all age groups, from babies through children and adults and elderly people, in various sorts of activities (Figure 30).
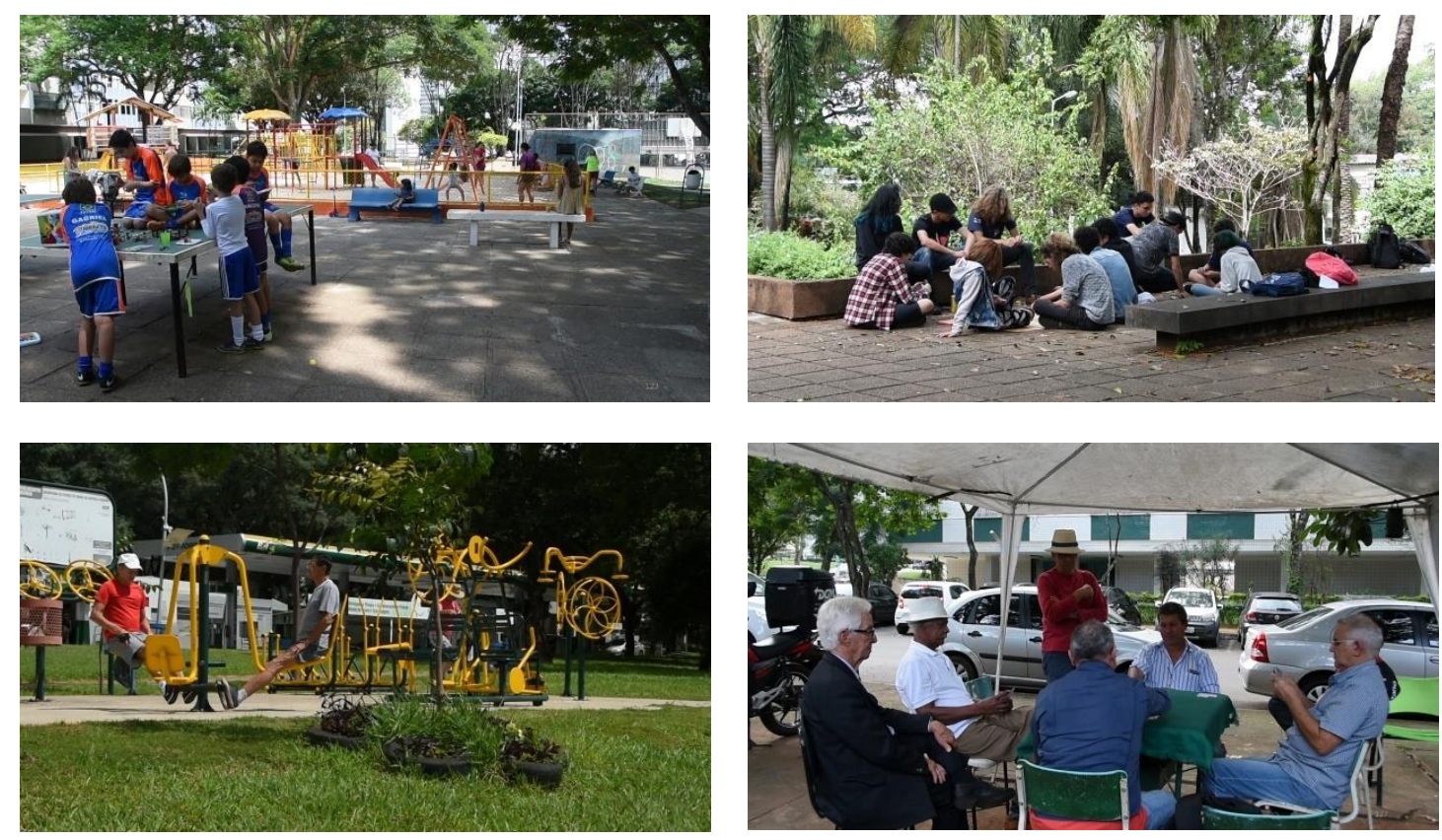

Figure 30 Use of public space in the superblocks by all age groups. (Source: the Author.)

The problem, then, is not how many but who use the place: it is the economic performance of the superblocks, highly valued by the market to the point of making them only accessible to higher income layers, thus resulting in their elitist appropriation. In contrast to main stream urban research, it is not simply localization that highly correlate with real estate prices, the building types of domestic space matters importantly: in same boroughs property values may vary immensely according to such types - i.e., their local, not global properties, as I have shown elsewhere(F. d. R. B. Holanda, 2007). Lucio Costa believed that simply the variation in size and finishing would imply adequate variation in prices which would suit all income layers (Costa, 1995). Wrong. The "superblock type" is expensive, a much greater typological variety would be needed so that a greater social diversity might happen here - as in Vila Planalto, a borough that dates from the initial stages of the building of the city, extremely central $(1.500 \mathrm{~m}$ from the Square of the Three Powers, the governmental core), the social stratification of which is close to that of the city as a whole, in fact, housing more poor people and less rich people, proportionally, than the whole municipality (Figure 32)(Holanda, 2010a).

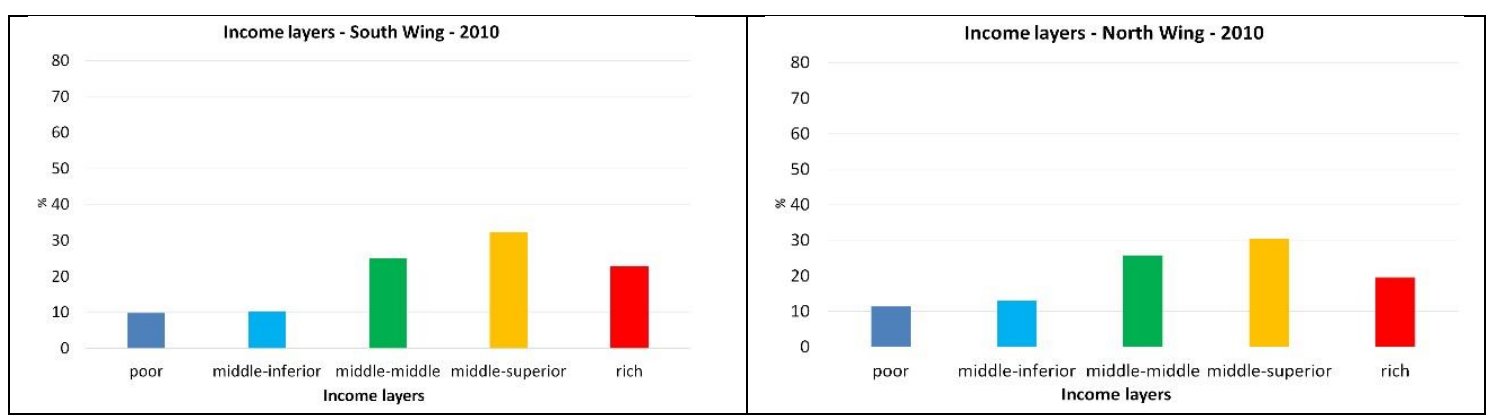

Figure 31 Income layers in the South Wing (left) and in the North Wing (right) or the Pilot Plan. (Source: IBGE, 2011.) 


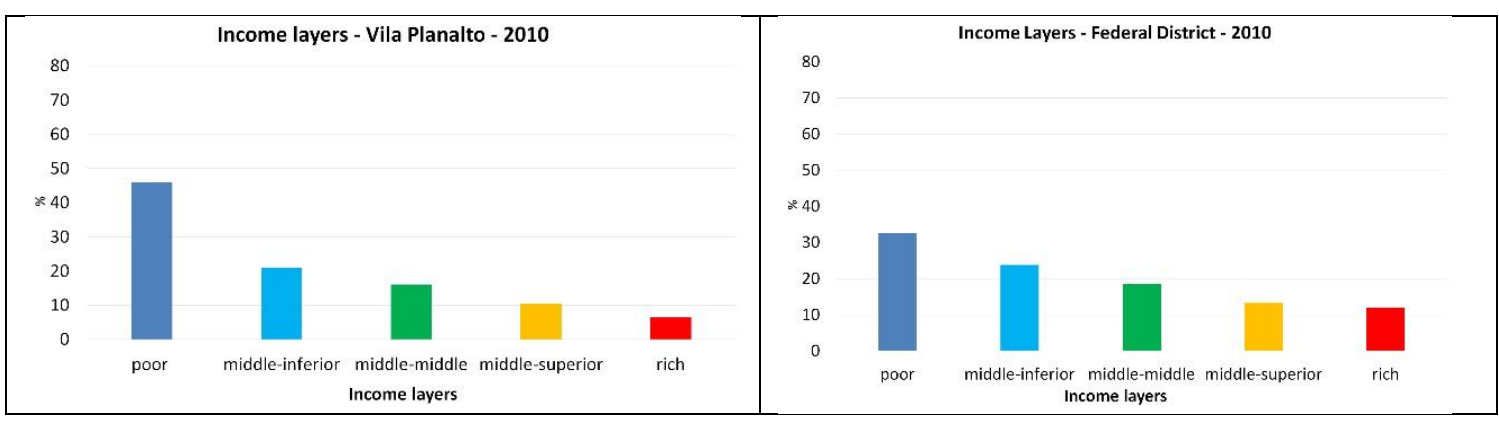

Figure 32 Income layers in Vila Planalto (left) and in Brasília as a whole (right). (Source: IBGE, 2011.)

\section{Conclusion}

Brasilia's superblocks and the city of Brasilia as a whole are well evaluated by all income layers, as a classic study by Machado and Magalhães has demonstrated, since back there in the 1980's (Machado \& Magalhães, 1985). And it continues so, despite mythical discourses that demonize them - both the superblocks and the city. However, even strictly obeying the norms, and within the present legal limitations (an elitist configuration) we can do better. Figure 33 summarises the attributes of the previous experiences and the design for the SQN-109.

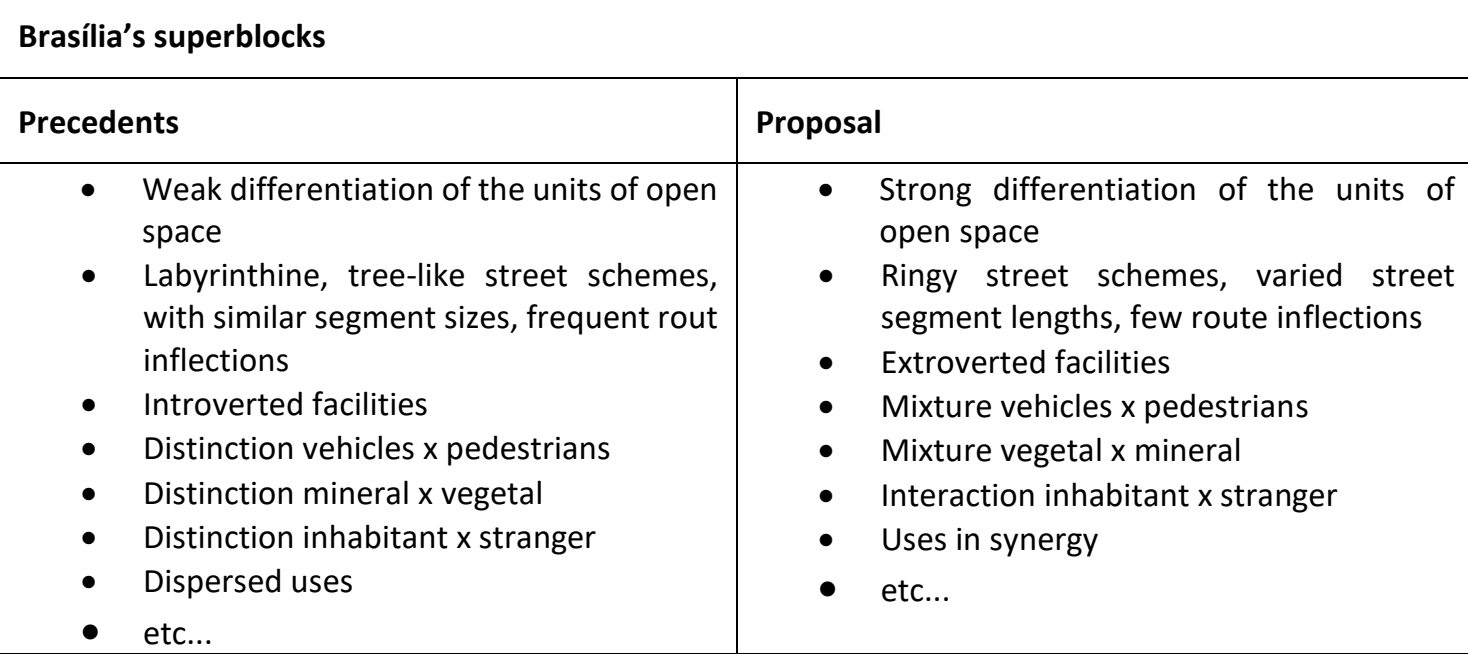

Figure 33 Brasília's superblocks. Attributes of previous examples $x$ attributes of the SQN-109 superblock. (Source: the Author.)

However, the performance of the SQN-109 awaits a more robust empirical test; it will take some time until we have the proposal implemented in its complete form, so that a more thorough evaluation can be made. At any rate, the "superblock type" houses a high-middle class stratus. Being one of the two only building types for domestic space proposed by Lucio Costa for the Pilot Plan (the second one were the "individual houses" by the lake, which were not the concern in this paper) (Costa, 1995), the superblocks are not an example to be followed if we wish socially diverse boroughs - the most telling example being, in Brasília, Vila Planalto. Even if the superblock may be "one of the most innovative and righteous contributions for multifamily housing schemes", ${ }^{4}$ in the city as a whole, and in each of its boroughs in particular, in order to favour social diversity at the former and at the latter, not just superblocks should be built (as it became the urbanistic motto in the Capital), not even multifamily schemes only: to house everyone, the city, today, and each and every one of its boroughs have to be necessarily typologically much more varied than this - Vila Planalto, here, and Copacabana, in Rio de Janeiro (the borough has similar social strata as the city as a whole), are great examples to emulate (IBGE, 2011).

${ }^{4}$ Idem, p. 326. 
Nonetheless, planning rules and the design of new boroughs insist on homogeneous neighbourhoods for the poor, or for the rich, or for the middle classes. There seems to be no way out within the State apparatus. A better and less unequal city will depend on the organization of Civil Society and its social movements to bring more social justice to the city (Harvey, 2012).

\section{References}

Benedikt, M. (2020). Architecture beyond experience: Applied Research and Design.

Costa, L. (1995). Lucio Costa: registro de uma vivência. São Paulo: Empresa das Artes.

Ferreira, M. M., \& Gorovitz, M. (2009). A invenção da superquadra. Brasilia: Iphan.

Giddens, A. (1984). The constitution of society.

Harvey, D. (2012). Rebel cities: From the right to the city to the urban revolution: Verso books.

Hillier, B. (1996). Space is the machine: a configurational theory of architecture. Cambridge: Cambridge University Press.

Hillier, B., \& Hanson, J. (1984). The social logic of space. Cambridge Cambridge university press.

Hillier, B., \& Leaman, A. (1974). How is design possible? Journal of Architectural Research, 3(1), 4-11.

Hillier, B., \& Leaman, A. (1976). Architecture as a discipline. Journal of Architectural Research, 5(1), 28-32.

Holanda, F. d. (2002). O espaço de exceção (2a ed. Brasília: FRBH, 2018. Disponível em: https://www.academia.edu/36395002/O_ESPA\%C3\%870_DE_EXCE\%C3\%87\%C3\%830_Livro_complet o_. Acesso em: 16 out. 2019. ed.). Brasília: Editora Universidade de Brasília.

Holanda, F. d. (2007). Arquitetura sociológica. Revista brasileira de estudos urbanos e regionais, 9(1), 115129.

Holanda, F. d. (2010a). Brasília: cidade moderna, cidade eterna. Brasília. Brasília: FAU-UnB.

Holanda, F. d. (2010b). Sociological architecture: a particular way of looking at places. The Journal of Space Syntax, 1(2), 355.

Holanda, F. d. R. B. (2007). Be aware of local properties. Paper presented at the International Space Syntax Symposium, Istanbul.

Holston, J. (1989). The modernist city: An anthropological critique of Brasília. Chicago University of Chicago Press.

IBGE. (2011). IBGE. Base de informações do Censo Demográfico 2010: resultados da Sinopse por setor censitário. Rio de Janeiro. Retrieved from

Jacobs, J. (1961). The death and life of great American cities. Ney York: Random House.

Kohlsdorf, G., \& Kohlsdorf, M. E. (2017). Ensaio sobre o desempenho morfológico dos lugares. Brasília: FRBH, 260-294.

Lynch, K. (1960). The image of the city: MIT press.

Machado, L. Z., \& Magalhães, T. Q. (1985). Imagens do espaço: imagens da vida. In: PAVIANI, A. (Org.) Brasília, ideologia e realidade: São Paulo: Projeto.

Popper, K. (2003 (1963)). Conjeturas e refutações. Lisboa: Almedina.

Turner, A. (2004). Depthmap 4: a researcher's handbook Technical report. London: Bartlett School of Graduate Studies, University College London. Retrieved from http://eprints.ucl.ac.uk/view/subjects/14500.html

\section{Resume}

Frederico de Holanda (b. 1944, Recife, Brazil), architect (BSc, Universidade Federal de Pernambuco, 1966), PhD in Architecture (University of London, 1997). Full Professor of Architectural History and Theory, Faculty of Architecture and Urbanism, University of Brasilia, where he has worked since 1972. Retired in 2014, but still contributing to the same institution as Senior Research Fellow. In 2019 he was awarded the title of Emeritus Professor of the University of Brasilia. He investigates relations between building and urban configuration, on the one hand, and public open space use, socio-spatial segregation and power relations, on the other. 31 MSC dissertations and 17 Doctoral theses have been concluded under his supervision. His doctoral thesis, supervised by Professor Bill Hillier (1997) - Exceptional Space - was granted the Prêmio Brasileiro Política e Planejamento Urbano e Regional, 1998 [Urban and Regional Planning and Policy Brazilian Prize] by the Associação Nacional de Pós-Graduação e Pesquisa em Planejamento Urbano e Regional - ANPUR [National Association of Urban and Regional Planning and Research]. Books published: $O$ espaço de exceção 
[Exceptional space], based in his PhD Thesis (Edunb, 2002); Arquitetura e Urbanidade [Architecture and Urbanity] (ed.) (ProEditores Associados Ltda., 2003; 2nd Edition, FRBH, 2011); Brasilia: cidade moderna, cidade eternal [Brasilia: modern city, eternal city], granted the ENANPARQ 2012 National Prize (FAU UnB, 2010); the bilingual book - Portuguese and English - Oscar Niemeyer: de vidro e concreto / of glass and concrete (FRBH, 2011); Exceptional Space (e-book format, FRBH, 2011); Ordem e desordem: arquitetura e vida social [Order and disorder: architecture and social life] (ed.) (FRBH, 2012); 10 mandamentos da arquitetura [10 commandments of architecture] (FRBH, 2013). In 2010 he founded a press to publish books on architecture (FRBH). He coordinates the research group "Dimensões Morfológicas do Processo de Urbanização" [Morphological Dimensions of the Urbanisation Process], registered in CNPq's [Brazilian National Research Council] since 1986. Senior Research Fellow, CNPq. He belongs to scientific committees and editorial boards in Brazil and abroad. He is married to Rosa de Lima, has two children - Joana and Pedro - and two granddaughters - Irene and Carolina. More info in: em http://www.fredericodeholanda.com.br; //fredericoholanda.academia.edu;

https://www.youtube.com/channel/UC8GKmH2AMAxMS4eINOIHD7Q/videos 